\title{
AN ELECTROSTATIC RADON MONITOR FOR MEASUREMENTS OF ENVIRONMENTAL RADON
}

\author{
Takao Iida, Yukimasa Ikebe, and Keiji Tojo*
}

Department of Nuclear Engineering, Faculty of Engineering, Nagoya University, Furo-cho, Chikusa-ku, Nagoya 464-01, Japan

\begin{abstract}
Authors developed a new field instrument for the measurement of environmental radon $(222 \mathrm{Rn})$ concentrations. The collecting electrode located at the center of a 32-L cylindrical vessel consists of a light pipe covered with aluminized Mylar coated with $\mathrm{ZnS}(\mathrm{Ag})$. Positive 218 Po (RaA) ions resulting from the decay of $222 \mathrm{Rn}$ are electrostatically collected on the Al Mylar, and the $\alpha$-scintillations produced in the underlying $\mathrm{ZnS}(\mathrm{Ag})$ are detected by a $52 \mathrm{~mm}$ photomultiplier tube. The $222 \mathrm{Rn}$ concentrations are calculated from $\alpha$-counts at one-hour intervals by using a personal computer, and stored on a floppy disk. The ${ }^{222} \mathrm{Rn}$ monitor is capable of measuring ${ }^{222} \mathrm{Rn}$ concentrations down to about $0.17 \mathrm{~Bq} \cdot \mathrm{m}^{-3}$.
\end{abstract}

\section{Introduction}

Ionization chamber (Budnitz, 1974), scintillation cell (Lucas, 1957), two-filter method (Thomas and LeClare, 1970) and electrostatic collection method (Dula and Dula, 1971; Wrenn et al., 1975) have been used for measuring environmental $222 \mathrm{Rn}$ concentrations. These instruments and methods reported up to the present have low sensitivity or lack stability and availability. The authors constructed a new field instrument with high accuracy and sensitivity for measuring the $222 \mathrm{Rn}$ concentration in grab sampling air collected at various environments. The ${ }^{222} \mathrm{Rn}$ monitor which was developed from the electrostatic continuous $222 \mathrm{Rn}$ monitor (I ida, 1985) can also measured the outdoor ${ }^{222} \mathrm{Rn}$ concentrations every one-hour. The present paper describes the construction and the characteristics of the improved ${ }^{222} \mathrm{Rn}$ monitor and the some results of grab sampling and continuous measurements.

2. Electrostatic ${ }^{222} \mathrm{Rn}$ monitor

Figure 1 shows the schematic diagram of the electrostatic $222 \mathrm{Rn}$ monitor for measuring the ${ }^{222} \mathrm{Rn}$ concentrations in grab sampling. The ${ }^{222} \mathrm{Rn}$ monitor consists of a cylindrical vessel of stainless steel which is able to be evacuated. The cylindrical vessel has a volume of about $32 \mathrm{~L}$. The sampling air is passed through a membrane filter and a vapor trap to the 32-L cylindrical vessel. Then, aerosols, ${ }^{222} R n$ daughters and water vapor were removed in the air.

Radon-222 decays by emission of an $\alpha$-particle to ${ }^{218}$ Po (RaA), and most ${ }^{218}$ Po atoms are positively charged (Dua et al., 1983). The positive ${ }^{218}$ Po ions are collected electrostatically on the electrode of aluminized Mylar $\left(0.9 \mathrm{mg} \cdot \mathrm{cm}^{-2}\right)$ coated with $\mathrm{ZnS}(\mathrm{Ag})$ phosphor of $10 \mathrm{mg} \cdot \mathrm{cm}^{-2}$. Alpha-particles emitted from the ${ }^{222} \mathrm{Rn}$ daughters are incident on the underlying $\mathrm{ZnS}(\mathrm{Ag})$ through the Al Mylar. The scintillations due to $\alpha$-particles are detected by a $52 \mathrm{~mm}$ photomultiplier tube optically coupled to a light pipe. The scintillation pulse which is amplified and processed is fed into a personal computer (NEC PC-9801RX) through the interface. Using the personal computer, the ${ }^{222} \mathrm{Rn}$ concentrations are calculated from $\alpha$-counts at one-hour

* Present address : Mitsubishi Electric Corp., 1-10 Tsukaguchi Honmachi 8-Chome, Amagasaki, Hyogo 661 JAPAN 


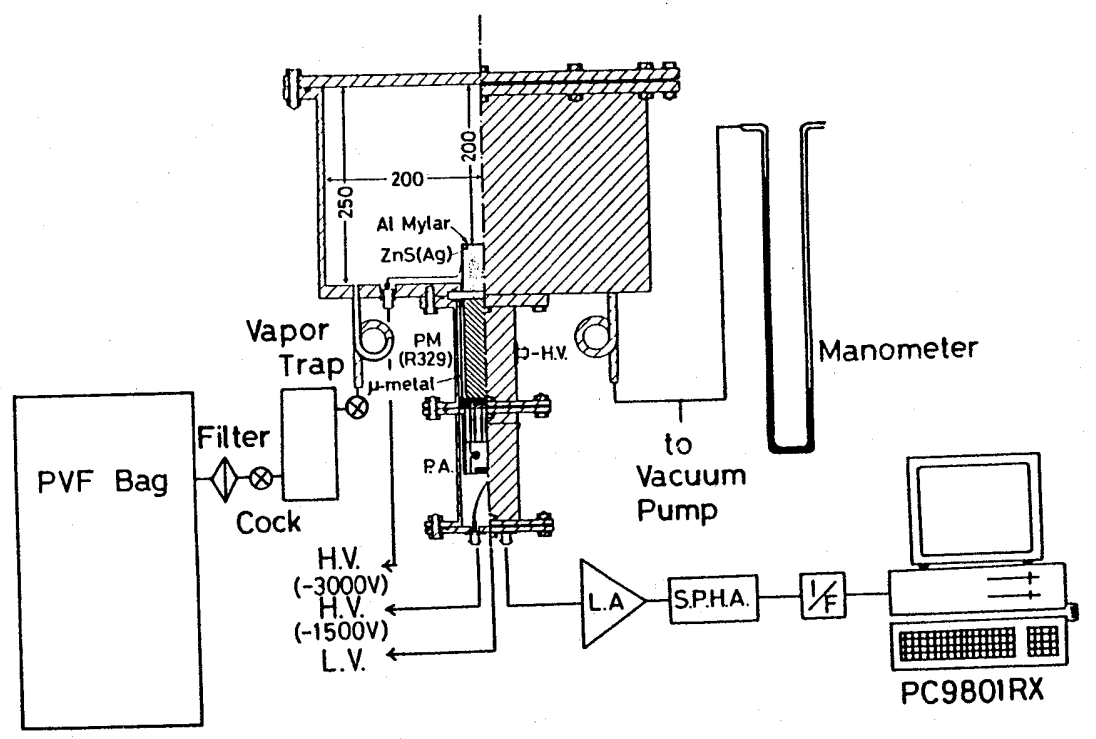

Fig. 1. Schematic diagram of the electrostatic ${ }^{222} \mathrm{Rn}$ monitor.

intervals on the basis of Batemann equation (Iida, 1985). The obtained $222 \mathrm{Rn}$ concentration data are stored on a floppy disk.

3. Characteristics of the $222 \mathrm{Rn}$ monitor

Figure 2 shows the equipotential surfaces and the lines of electric force inside the $222 \mathrm{Rn}$ monitor obtained by using a computer (Iida, 1985). From the electric field and the lines of electric force, the effective collection volume can be calculated to be $20.5 \mathrm{~L}$.

The electrostatic collection of $218 \mathrm{Po}^{+}$ions depends on the humidity of the air and the collecting potential. In particular, the effect of humidity is an important problem for the electrostatic ${ }^{222} \mathrm{Rn}$ monitor (Dua et al., 1983). The air sample was passed through a vapor trap of phosphorus pentoxide $\left(\mathrm{P}_{2} \mathrm{O}_{5}\right)$ to maintain the absolute humidity in the chamber less than

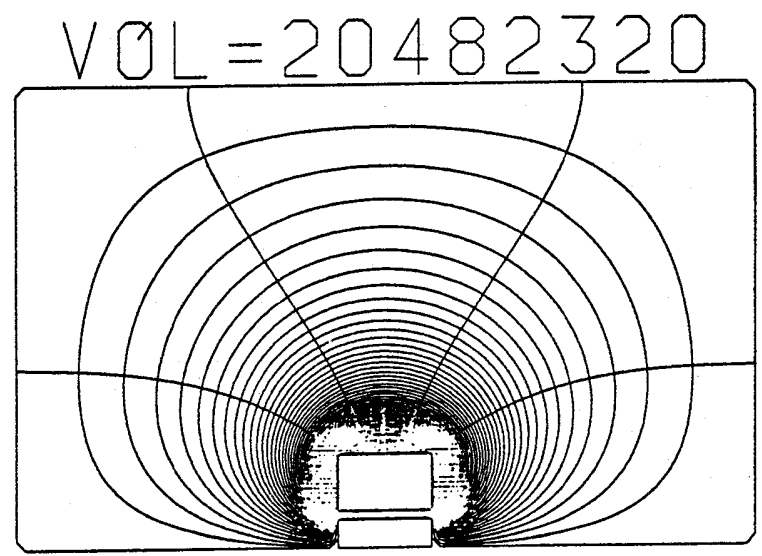

Fig. 2. Electric field calculated by iterative method. 
$0.5 \mathrm{~g} \cdot \mathrm{m}^{-3}$. The dependence of the collection efficiency upon the applied potential was measured from $500 \mathrm{~V}$ to $5000 \mathrm{~V}$ in step of $500 \mathrm{~V}$, keeping the humidity at about $0 \mathrm{~g} \cdot \mathrm{m}^{-3}$. The experimental result showed that the collection efficiency increased only $18 \%$ from $500 \mathrm{~V}$ to $5000 \mathrm{~V}$. Therefore, the applied potential has been determined to be $3000 \mathrm{~V}$ considering the possibility of electric discharge.

A calibration of the $222 R n$ monitor was done as follows: after air containing ${ }^{222} \mathrm{Rn}$ had been introduced into a 1.5-L cylindrical ionization chamber to measure the $222 \mathrm{Rn}$ concentration, the air was injected into the $32-\mathrm{L}$ cylindrical vessel of the ${ }^{222} \mathrm{Rn}$ monitor. The ${ }^{222} \mathrm{Rn}$ concentration in the ${ }^{222} \mathrm{Rn}$ monitor was calculated considering the volume ratio of the $32-\mathrm{L}$ vessel and the 1.5-L ionization chamber. The calibration factor between measured $\alpha$-counts and ${ }^{222} \mathrm{Rn}$ concentration was derived to be $(53.7 \pm 0.9)$ counts $\cdot h^{-1} \cdot\left(\mathrm{Bq} \cdot \mathrm{m}^{-3}\right)^{-1}$.

The measurement of the background count rate of the $222 \mathrm{Rn}$ monitor was carried out by introducing radon-free air into the $222 \mathrm{Rn}$ monitor. From this experiment, the mean background count rate was obtained to be $(5.0 \pm$ 2. 0 ) counts $\cdot h^{-1}$. Using the values of the background count rate and the calibration factor, the detection limit defined by Currie (Currie, 1968) is found to be $0.17 \mathrm{~Bq} \cdot \mathrm{m}^{-3}$.

\section{Sampling measurements}

For example of the grab sampling measurements, the electrostatic ${ }^{222} \mathrm{Rn}$ monitor was applied to measure $222 \mathrm{Rn}$ exhalation rate from the soil. The diagram of the sampling system is shown in Fig. 3. A 3.1-L stainless-steel cylindrical container (28 cm in diameter and $10 \mathrm{~cm}$ in height) is pressed into the soil to a depth of $1 \mathrm{~cm}$ and left for $15 \mathrm{~min}$. There is no effect of back diffusion of $222 \mathrm{Rn}$ into the soil for the accumulation time. After 15 min, the air in the 3.1-L container is passed to a 5-L polyvinyl fluoride (PVF) sampling bag with a diaphragm pump. The outdoor air in the vicinity of the sampling point is also collected in a 50-L PVF sampling bag. The $222 \mathrm{Rn}$ concentration in the 5-L PVF sampling bag was measured as follows: The air in the PVF bag is dehumidified and injected into the $32-L$ vessel of the ${ }^{222} \mathrm{Rn}$ monitor which has been evacuated beforehand. Moreover, radon-free air is added into the $32-\mathrm{L}$ vessel unt il its pressure reaches $1 \mathrm{~atm}$. Then, the ${ }^{222} \mathrm{Rn}$ concentration is measured with the electrostatic $222 \mathrm{Rn}$ monitor. The $222 \mathrm{Rn}$ concentration in the 50-L PVF bag is also measured as shown in Fig. 1 . The ${ }^{222} \mathrm{Rn}$ exhalation rate from the soil is given by

$$
E=\frac{\left(Q-Q_{a} i r\right)}{r \cdot S \cdot T}
$$

where $\mathrm{E}\left(\mathrm{Bq} \cdot \mathrm{m}^{-2} \cdot \mathrm{s}^{-1}\right)$ is the ${ }^{222} \mathrm{Rn}$ exhalation rate from the soil, $\mathrm{Q}\left(\mathrm{Bq} \cdot \mathrm{m}^{-3}\right)$ is the ${ }^{222} \mathrm{Rn}$ concentration in the 5-L PVF bag, Q Q ir $\left(\mathrm{Bq} \cdot \mathrm{m}^{-3}\right)$ is the $222 \mathrm{Rn}$ concentration in the 50-L PVF bag, $r$ is the passing efficiency of $222 \mathrm{Rn}$ from the 3.1-L container to the 5-L PVF sampling bag, $S\left(\mathrm{~m}^{2}\right)$ is the base area of the 3.1-L cylindrical container, and $\mathrm{T}(\mathrm{s})$ is the setting time of the 3.1-L container. The passing efficiency $r$ was determined to be $(0.50 \pm 0.9)$ on experiment.

The ${ }^{222} \mathrm{Rn}$ exhalation rates were measured from Aug. to Dec. 1988 at 14 locations in the campus of Nagoya University and its vicinities. Figure 4 shows the average and standard deviation of 10 measurements of the $222 \mathrm{Rn}$ exhalation rate at each point. The analysis of variance indicates that there are significant differences in the exhalation rate at each point. The average ${ }^{22} \mathrm{Rn}$ exhalation rate of 14 locations was $(10 \pm 1.6) \mathrm{mBq} \cdot \mathrm{m}^{-2} \cdot \mathrm{s}^{-1}$. 


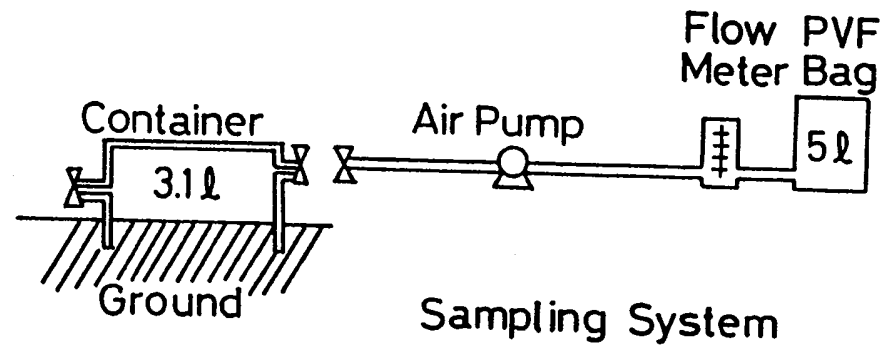

Fig. 3. Diagram of sampling system for the measurement of $222 \mathrm{Rn}$ exhalation rate.

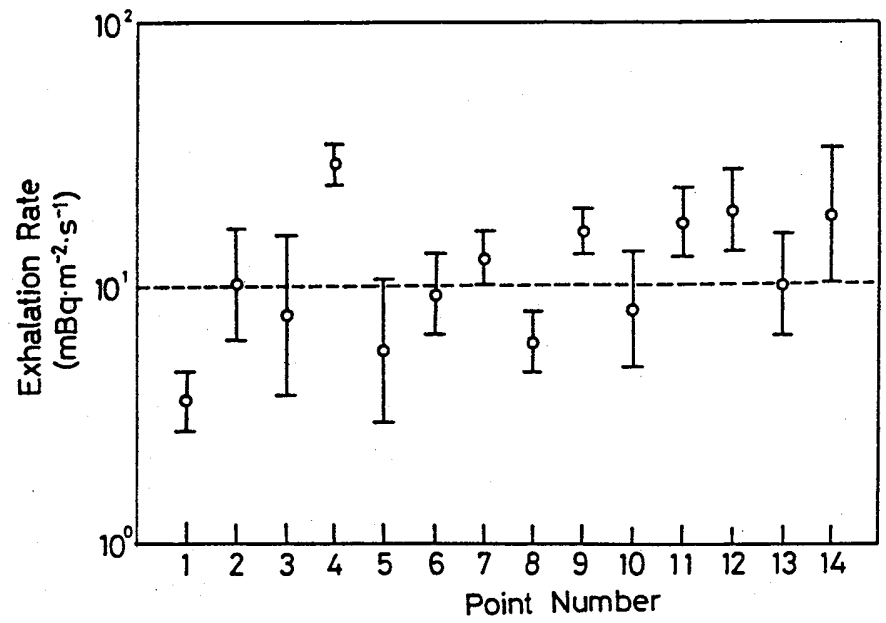

Fig. 4. Range of ${ }^{222} \mathrm{Rn}$ exhalation rates in the campus of Nagoya University and its vicinities.

5. Continuous measurements

A flow rate of $1 \mathrm{~L} \cdot \mathrm{min}^{-1}$ was used for continuous measurement, considering the exchange rate of the air in the ${ }^{222} \mathrm{Rn}$ monitor, the effect of $220 \mathrm{Rn}$ concentration in the sampling air and the amount of drying agent in the vapor trap. Figure 5 shows the typical diurnal variation of outdoor $222 \mathrm{Rn}$ concentrations measured with the electrostatic ${ }^{222} \mathrm{Rn}$ monitor. The ${ }^{222} \mathrm{Rn}$ daughters concentrations have also been measured by filter pack method during the same period. The ${ }^{222} \mathrm{Rn}$ daughters concentrations are lower than the ${ }^{222} \mathrm{Rn}$ concentrations, because of non-radioactive equilibrium between $222 R n$ and its daughters in outdoor air. However, the 222Rn and its daughters show similar variation as is shown in Fig. 5 .

6. Conclusions

In the present study, a new type electrostatic $222 \mathrm{Rn}$ monitor was developed for measuring not only outdoor $222 R n$ concentration levels continuously but also the ${ }^{222}$ Rn concentration in grab sampling air. From the relationship between measured $\alpha$-counts and $222 \mathrm{Rn}$ concentration, the calibration factor was derived to be $(53.7 \pm 0.9)$ counts $\cdot h^{-1} \cdot\left(B q \cdot \mathrm{m}^{-3}\right)^{-1}$. The 


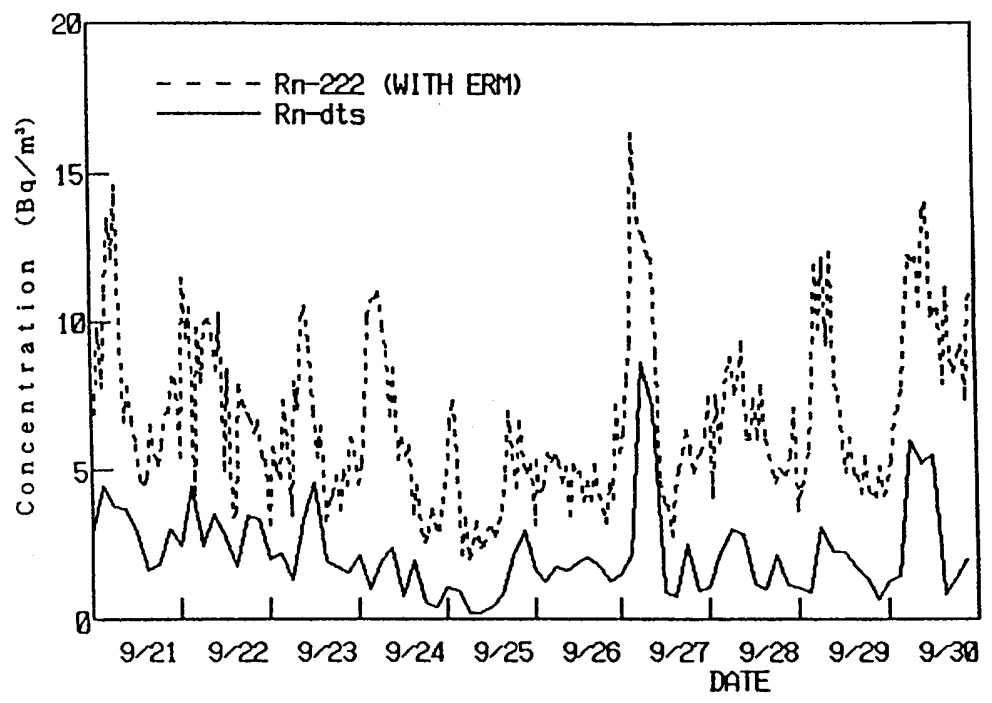

Fig. 5. Comparison of $222 R n$ concentrations measured with electrostatic ${ }^{222} \mathrm{Rn}$ monitor and by filter pack method.

detection limit of the ${ }^{222} \mathrm{Rn}$ concentration measured at one-hour intervals was found to be $0.17 \mathrm{~Bq} \cdot \mathrm{m}^{-3}$. Therefore, outdoor ${ }^{222} \mathrm{Rn}$ level can be measured with high accuracy.

The $222 \mathrm{Rn}$ monitor was applied to the grab sampling and continuous measurements. The results show that the ${ }^{222} \mathrm{Rn}$ monitor has high sensitivity, stability and availability.

\section{References}

Budnitz, R. J., Radon-222 and its daughters - A review of instrumentation for occupational and environmental monitoring, Health Phys., 26, 145-164, 1974.

Currie, L. A., Limits for qualitative detection and quantitative determination, Anal. Chem., 40, 586-593, 1968.

Dua, S. K.. P. Kotrappa, and P. C. Gupta, Influence of relative humidity on the charged fraction of decay products of radon and thoron, Health Phys. , $45,152,1983$.

Dula, G. and G. A. Dalu, An automatic counter for direct measurements of radon concentration, Aerosol Sci., 2, 247-255, 1971.

Iida, T., An electrostatic radon monitor for the continuous measurement of environmental radon, in Atmospheric Radon Progeny and environmental Radioactivity, edited by S. Okabe, Atomic Energy Society of Japan, Tokyo, pp. 65-73, 1985 (in Japanese).

Lucas, H. F., Improved low-level alpha-scintillation counter for radon, Rev. Sci. Instrum., 28, 680-683, 1957.

Thomas, J. W. and P. C. LeClare, A study of the two-filter method for radon-222, Health Phys., 18, 113-122, 1970.

Wrenn, M. E., H. Spitz, and N. Cohen, Design of a continuous digital-output environmental radon monitor, IEEE Trans. Nucl. Sci., 22, 645-648, 1975.

$$
\begin{array}{r}
\text { (Received November 12, 1991; Revised December 13, 1991; } \\
\text { Accepted December 20, 1991.) }
\end{array}
$$

